\title{
Houseboats in Kerala - Constructional Features and Environmental Issues
}

\author{
Dr. Rymala Mathen \\ Asst. Professor, Faculty of Engineering, Avinashilingam University for Women Coimbatore-641043
}

\begin{abstract}
Kerala Houseboats (Riceboats) or kettuvallam are country boats that were used in early days for transport of goods from isolated interior villages of Kerala backwater area to the towns like Alleppey, Kollam, Cochin and Kottayam. With the advent of land transport facilities, gradually the kettuvalloms went off the scene. Now they are back again as a major tourist attraction as a modern moving boat house. They form a huge source of revenue and prosperity for the region. It is a well-known fact that only around 100 of the 600-plus houseboats operating in the Vembanad Lake and the surrounding canals and rivers have valid Pollution Control Certificates (PCC) since they have onboard sewage treatment facilities. Houseboats satisfying the essential conditions and adhering to eco-friendly measures will be awarded the Green Palm Certificate, the top classification awarded by the Department of tourism. The sustainability of eco-tourism lays in the four main areas - Environment - Energy - Water-Propulsion. Less fuel/running cost, no oil or diesel contamination into backwaters, no untreated sewage into backwater, reduction in noise pollution are the ways to achieve dream for a green and pleasing future in Kerala backwater and save the same for the next generation.
\end{abstract}

Keywords: Eco friendly tourism, Effluent treatment, Green palm Houseboat, Pollution Control Certificates (PCC), sustainability.

\section{Introduction}

The earth has enough for everyone's needs but not enough for some people's greed" Mahatma Gandhi

KERALA, sunny, lush, green State lies between the Lakshadweep Sea and the Western Ghat mountains in southern peninsular India. It is nourished by 44 rivers and a chain of backwaters. Its physiography and its culture are unique. The verdant forests, pristine rivulets and golden beaches are nature's priceless gifts to Kerala. The State, to a great extent, is still free from the scourges of industrialization. The people of Kerala are highly conscious of the need to protect the environment. Kerala is one of the 12 States of India whose legislatures passed resolutions requested to make laws to prevent and control water pollution. kspcb keralapcb.org[1]

The total contribution of travel and tourism to GDP, including its wider economic impact is $9.1 \%$ in 2010. The total employment created is worked out as 258 million which form $8.8 \%$ of global employment Kerala initiated tourism development programmes by establishing an international beach resort at Kovalam in 1976 with the patronage of central government. Realizing the economic potentials, Government of Kerala declared tourism as an industry in 1986. Within a short span of two and half decades, Kerala succeeded in establishing its tourism brand in the international market. (Ministry of Tourism, Government of India,2009[2] and WTTC, Travel and Tourism Impact, India 2011[3])

The Kettuvallom (House Boat in Kerala) is a large floating structure with high load carrying capacity was a part of Kerala's culture and heritage over the past years. Houseboats could sail harnessing wind energy. For centuries, Houseboat was an important mode of transportation in coastal Kerala just because of its accessibility to the most remote areas. Due to its sheer size and shape, houseboats can carry load, which is more than thrice that of a cargo truck. As time passed, motorized road, rail and air transportation scored over the slow and staid country boat, with people opting for speed over charm.

'God's Own Country' has managed to capture the attention of the international tourism market. Kerala's tourism brand is listed among the top 100 brands of India and has been accorded the highly coveted 'Super Brand' status. Kerala is cited as one of the 50 destinations of a lifetime by National Geographic Traveler, and is also a 'partner state' to the World Tourism and Travel Council.(http://www.Kerala-indiatourism.com/Kerala[4]

The tourist demand for an experience to get a feel of the Kerala shores brought the Houseboats back to the waters. They were attracted by the simplicity and the originality of the form, relishing the traditional Kerala cuisine and dishes made out of local fishes, served by the crew members. The tourists loved the slow and leisurely movement more than the monotonous motion of the mechanized ones. 
Nowadays environment friendliness has become the yardstick gauging the efficiency of transportation. Houseboat is not only economical but also non-polluting and environment friendly. It thus became imperative that this mode of transportation be developed further and encouraged.

\section{Objectives of the study:}

- To understand the constructional features of house boats

- To know the facilities available in a houseboat

- To study the impact of Houseboats on water environment

- To learn the specifications to be followed in houseboat services

\section{Methodology}

Methodology consists of site study, selection of method and selection of tool, conduct of study and analysis of data. The study was conducted at Alleppey in Kerala and was selected since Alleppey has the highest number of houseboats in Kerala. It is called the city of canals. Interlocked with a large number of canals and bridges, this water locked district has immense untapped potential for backwater tourism. Alappuzha, a centre of coir and carpet industries is an ideal place for backwater touring as well as for visits to the lovely church filled town of Kottayam, and the town of Aranmula where onam water activities take place. Muthoot River Escapes (MRE) - group Houseboat was selected as it is a reputed and an environment conscious boat company which follows the ecofriendly specifications. (http:// www.Kerala-india-tourism.com[4] / Kerala houseboats)[1]. Fig 1\&2. Case study method was used to find out the features of house boats in Kerala backwaters. (Jaspal Singh 2001)[5] A schedule was framed consisting of interactive session, being a non participant. This goes in verbal method of securing data in the field. It consists of facts, knowledge, beliefs, motivation and attitude. When questions are formulated for interactive session, it is important that it is clear and to the point. Questions must be plain and simple English, and it must be as short as possible (Sidhu, 1984)[6]. A rapport was developed between the investigators and the owners of houseboats to understand the materials and methods used in its construction and facilities inside, tariffs, sanitation and power supply

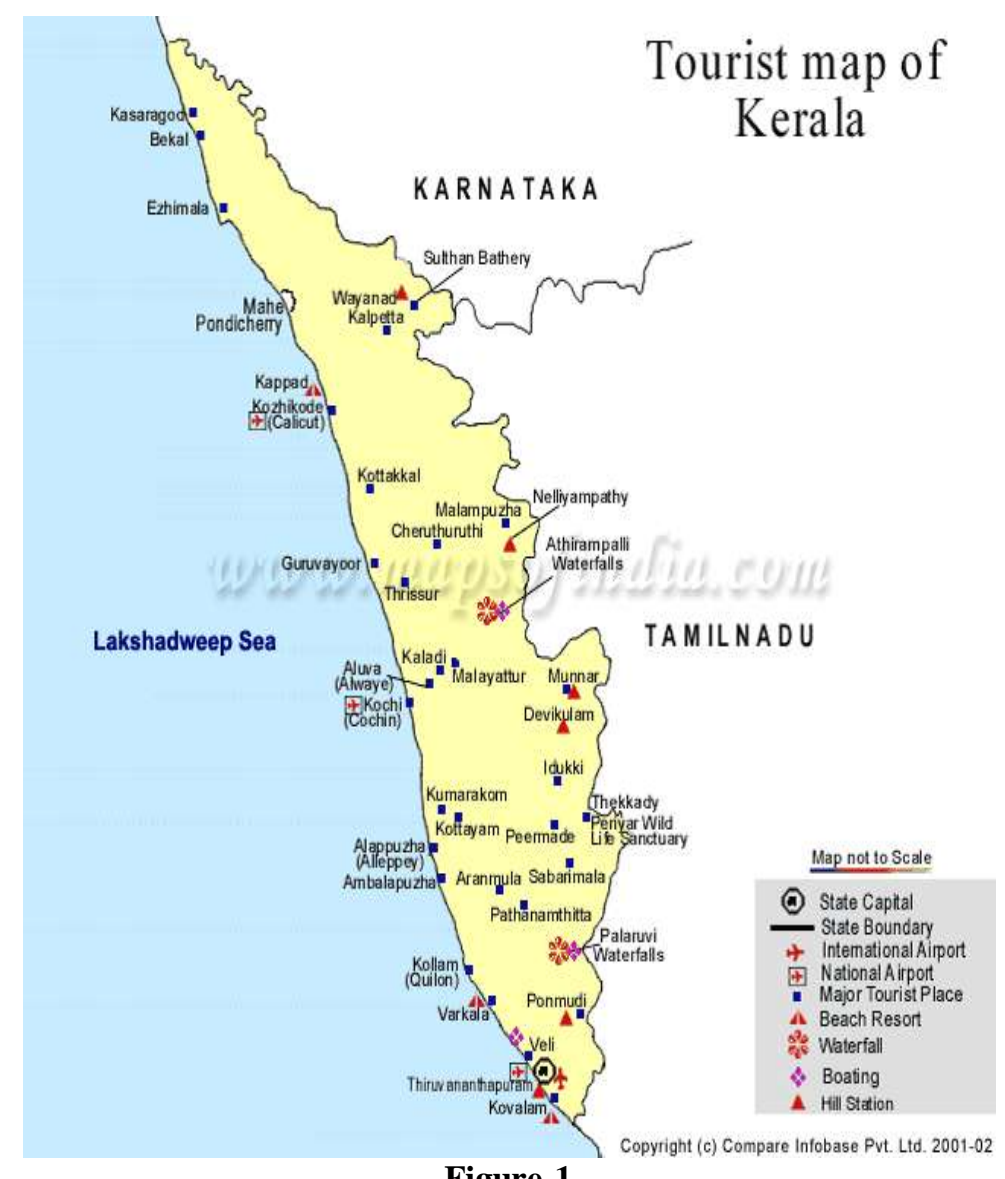

Figure-1 


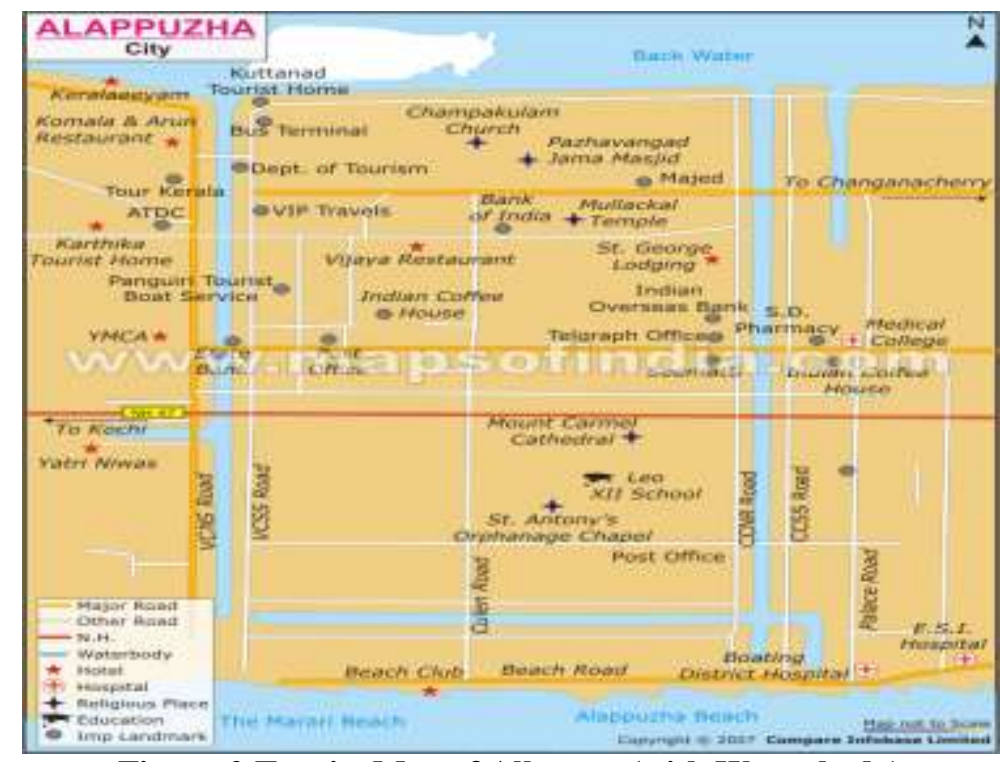

Figure:2 Tourist Map of Alleppey (with Water body)

\section{Results And Discussion}

Unique products like backwater tourism and ayurveda emerged as the innovation of tourism industry which attained international recognition. Currently there are about 1,000 houseboats in Kerala backwaters from basic to luxury resembling floating mini-palaces. Focusing on the need for community benefits and participation in tourism, Ecotourism models were conceived in the late 90s and the Responsible Tourism initiative was launched in 2007. (Kerala State Pollution Control Board,2008)[7]

Backwater based tourism activities are now concentrated in the Alappuzha region. More than a thousand houseboats are now operated in this region, resulting in some backwater stretches in this region with density much above the carrying capacity ( WTTC, Travel and Tourism Impact, India 2011)

This include

- Techniques in house boat construction

- Materials used for construction of house boats

- Plan of design and finishes used

- Facilities in a houseboat

- Impact of houseboats on water environment

- Specifications for houseboat services

\subsection{Techniques in house boat construction}

The two techniques of houseboats are the Kettuvallom- the traditional houseboat and the Kalpathi are the houseboats of today. Kalpathi the present houseboat has been developed from the Kettuvallom and so both has got similar features.

\section{Kettuvllom}

The Kettuvallom of Kerala is giant country crafts measuring up to $80-91$ feet in length. Traditionally, the houseboat was called Kettuvallam, which means a boat made by tying together pieces of wood. The entire boat was held together by knots in which not a single nail is used in the making of a Kettuvallam. Jack wood / or Anjili planks are joined together with coir rope and then coated with black resin made from boiled cashew nut shells.

\section{Kalpathi}

In recent times, the kettuvallom have been replaced by more and modern modes of transport called kalpathi .The boat is made up of Anhili (Arotocarpus) the planks, are joined by means of riveting. 


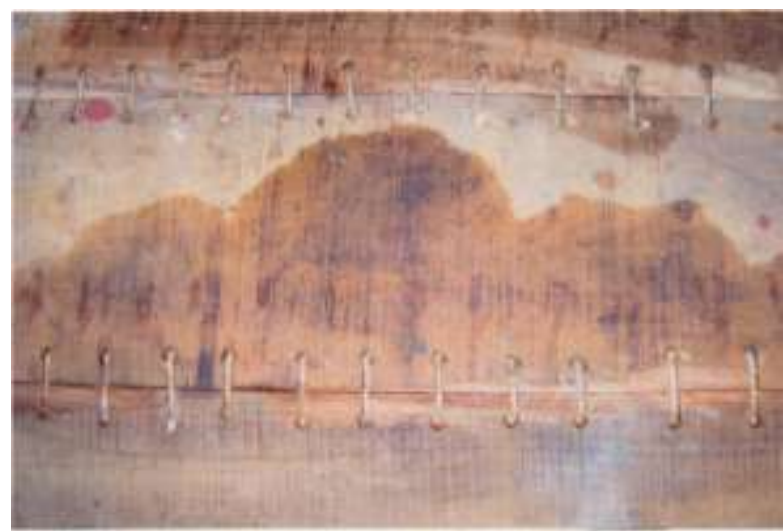

Kettuvallom

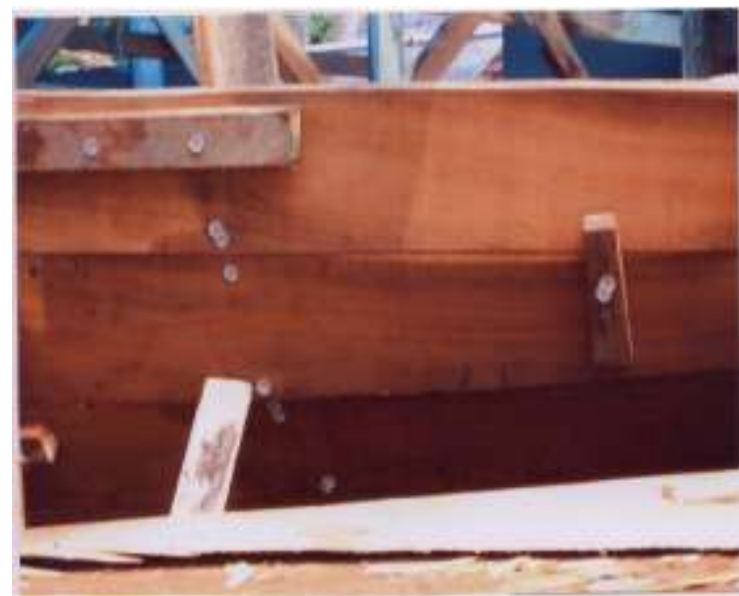

Kalpathi

Figure-3 Types of Houseboats

3.2.Materials used for construction of house boats

Materials used for Houseboat constructed include Anjhili, (Arotocarpus) Bamboo, Coir, Fiberglass, Marine Plywood, Chicken mesh, Rivet,

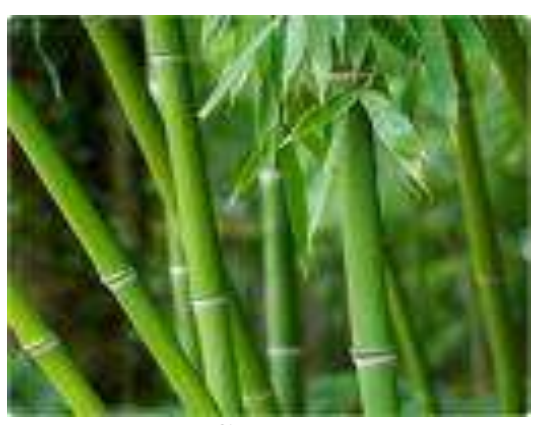

Green ply

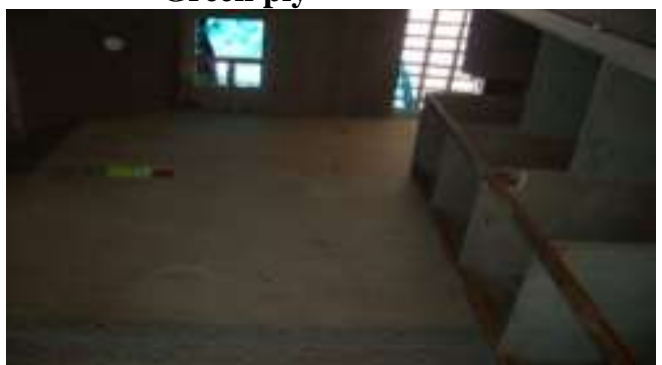

Marine plywood

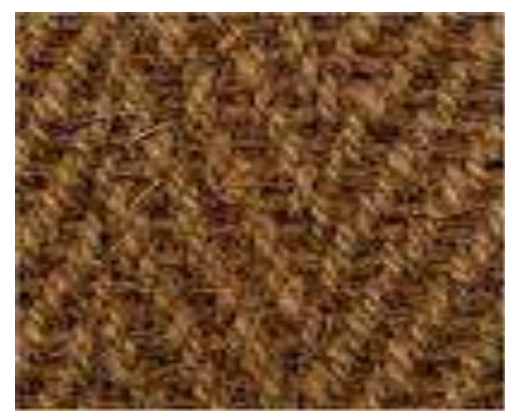

Coir

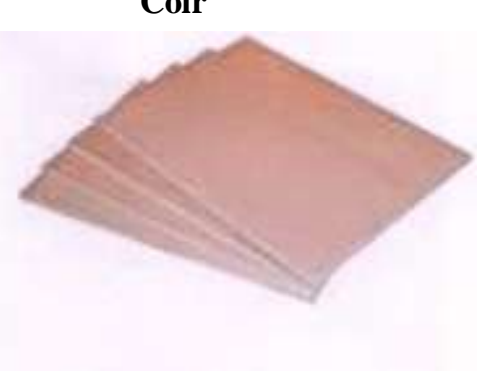




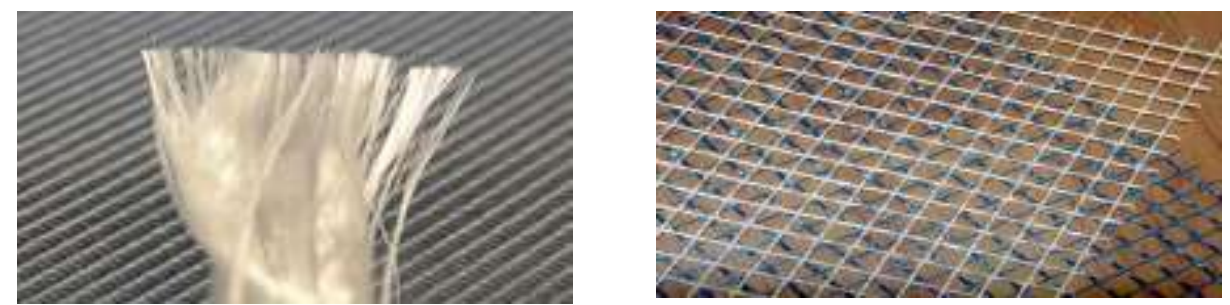

Fibre glass Chicken Mesh

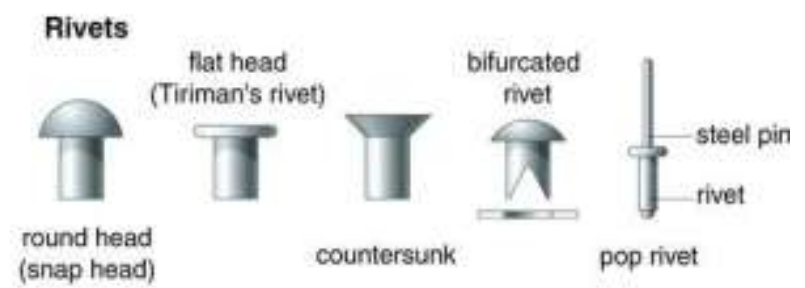

(http://en.wikipedia.org/wiki/Rivet[8])

Coir

Coir (from Malayalam kayar, cord) is a coarse fibre extracted from the fibrous outer shell of a coconut. Coir fibers are found between the husk and the outer shell of a coconut. The individual fiber cells are narrow and hollow, with thick walls of cellulose. They are pale when immature but later become hardened and yellowed as a layer of lignin is deposited on their walls, there are two varieties of coir. Brown coir is harvested from fully ripened coconuts. It is thick, strong and has high abrasion resistance. It is typically used in mats, brushes and sacking. The coir fiber is relatively water-proof and is one of the few natural fibers, resistant to damage by salt water. The major use of white coir is in rope manufacture.

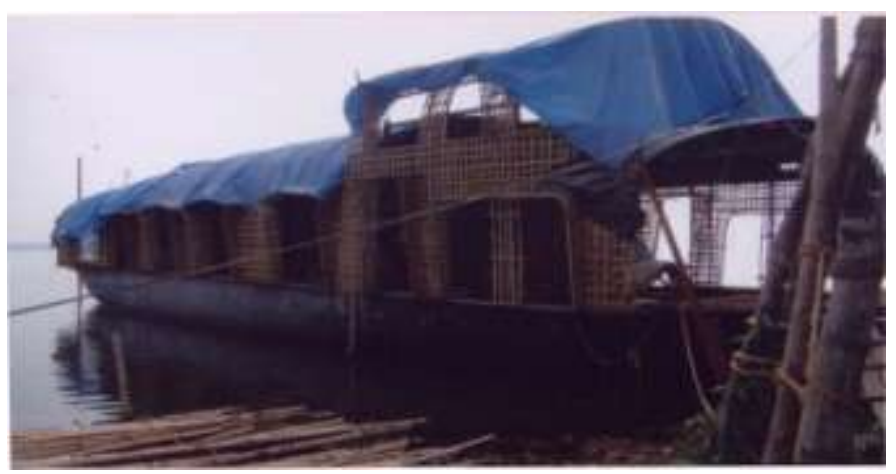

Fiber Glass

Fiberglass is material made from extremely fine fibers of glass. It is used as a reinforcing agent for many polymer products; the resulting composite material, known as fiber-reinforced polymer (FRP) or glassreinforced plastic (GRP) is called "fiberglass" in popular usage. (Loewenstein , K.L.1973)[9] Glass fibers are useful because of their high ratio of surface area to weight. By trapping air within them, blocks of glass fiber make good thermal insulation, with a thermal conductivity of 0.05 W/m-K.( Lubin, George(Ed.,) 1975[10]and MohrJ.G and Rowe,W.P,1978[11]

\section{Marine Plywood}

Marine Plywood is specially treated plywood that is designed to resist rotting in a high - moisture environment. Marine plywood is frequently used in the construction of docks and boats. Its advantages are durability, workability and resistance to warping (PSI-95, American Plywood Association,2001)[12]

Chicken mesh

Chicken wire mesh, which are made of galvanized iron wire and is used in poultry farms, estates, cages, on concrete layers and for insulation purposes. 


\section{Rivet}

A rivet is a mechanical fastener. Before it is installed it consists of a smooth cylindrical shaft with a head on one end. The end opposite the head is called the buck-tail. On installation the rivet is placed in a pre drilled hole. The stress and shear in a rivet is analyzed like a bolted joint. Rivets fill the hole where they are installed to establish a very tight fit (often called interference fit) it is difficult or impossible to obtain such a tight fit with other fasteners. (Segui, William T,2007)[13]

\subsection{Plan of design and finishes used}

\section{Floor plan}

- For the house to be constructed on the deck of the boat, first a detailed floor area plan has to be prepared.

- It is based on the final plan and format, the template is prepared and laid on a schematic floor.

- The floor area of the house on the deck is made with wooden planks

- The outer structure or the framework of the boat is alone with bamboo ribs and tied up with coir which will decide the shape of the roof.

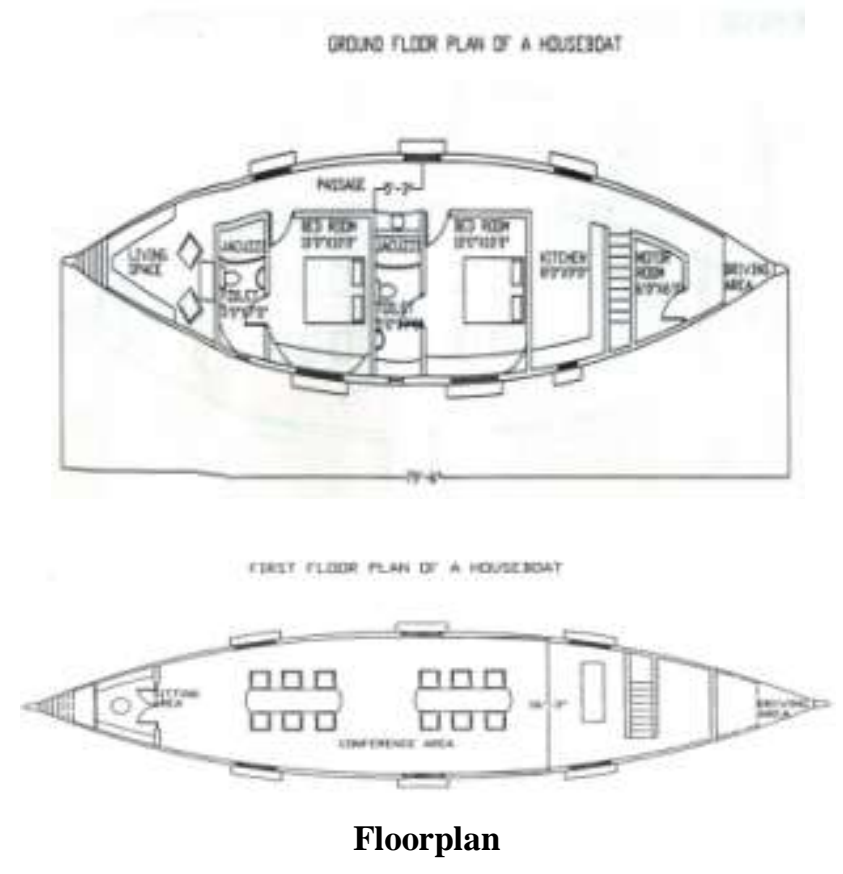

In the manufacturing of houseboat, eco-friendly and non perishable aluminum, ply woods tubs and frames are used to provides solid window structure which are then covered with seasoned plywood and teak wood (.RaoA.G. M and Murthy D.S.R(1995)[14]

Wall

Raised walls are plywood. Plywood used is marine plywood. The wood undergoes certain process to give a complete water proof wall finish. Wood is coated with fiber glass and then over that chicken mesh is laid. In to this, cement coating is given and over it can be given a wall putty or tile finish. This is followed for all walls including toilet (Wikipedia.org/marine plywood[15] and Volf Milos .B 1990 [16]

\section{SECTIDNS DF THE WALL}

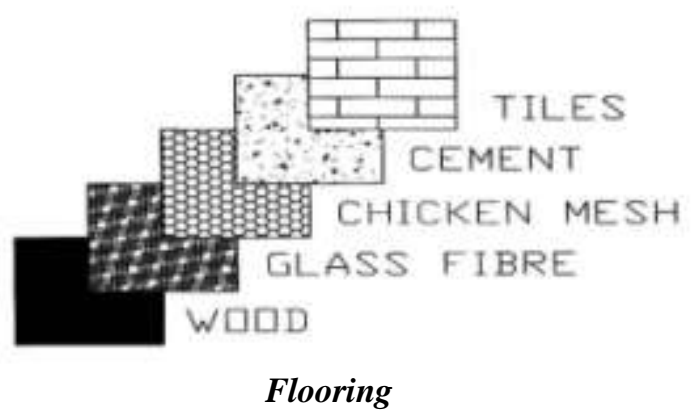


While laying the flooring, same kind of finish is done as for wall. Fiber glass is laid; over it cement coating followed by wooden floor finish. Best recommended floor finish is 'Pergo' wooden floor finishes.

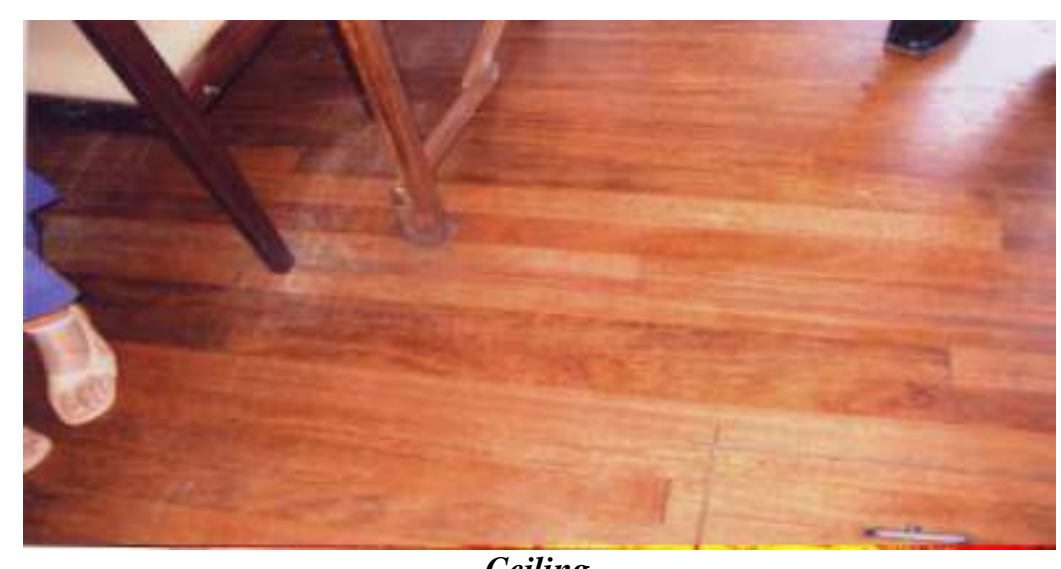

Ceiling

Low ceiling with curved frames are made above which the conduits and other electrical cables run through. The frames are covered with bind ply wood.

\section{Roofing}

The roof has been made of two layers of bamboo reeds, with a polythene layer in the middle. The area below this and the ceiling has been filled with thermocol to give maximum cooling effect. A $140 \mathrm{HP}$ engine powers the boat and solar panels have been fit on the roof. The roof is given an aero dynamic corned shaped with a wooden frame work made of Cheruthekku. (teak).The roof is covered with braided coconut palm leaves and flexible but marine plywood. This structure is worked with cashew or neem oil to make it more strong, flexible and water repellent.

\section{Low ceiling}

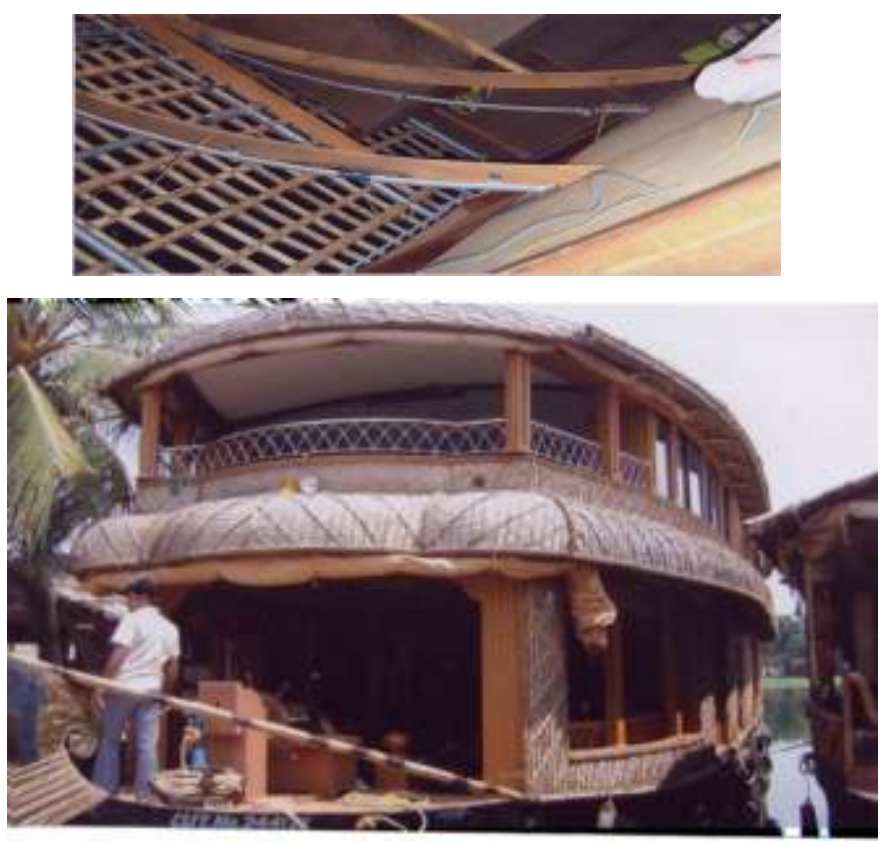

\subsection{Facilities in a houseboat}

Roof

Each houseboat is of excellent construction and luxurious furnishing with exquisite flooring, Hull and Valavara(canopy). Each houseboat is provided with a sun deck, spacious living/dining area, attached toilets, and separate toilets for crew. Some houseboats are basic and some are very luxurious. The sizes range from one to three bedrooms. The boats look pretty basic from the outside and are made of local products with all the facilities and comfort inside as in a modern house with fully furnished rooms- Bedroom, living and dining area, 
kitchen and toilet. Some have conference area too. Spacious passage and a neat, classy fire proof kitchen and with fire extinguishers.

Clean good quality linen, blankets, towels, etc. Log books and tourist records are updated regularly and the boat has a valid license. The service of professional cook is available on the boat.

\section{Peculiarities of Suite Boat:}

- Round the clock A/c

- Private upper desk (entry through bed room)

- Furnished and spacious Bed Room (21' X 13') .(plate15\&16)

- Spacious Bath Room with bath tub ( $8^{\prime}$ X 6')

- Special Menu.

- The energy for lighting, air conditioning, chilling and TV is provided by Solar Panels,

There is a new venture, a five bedroom A/c Houseboats with Conference hall. Skilled and experienced crew mans the craft and lifeguards at important points enhance the foolproof security system.

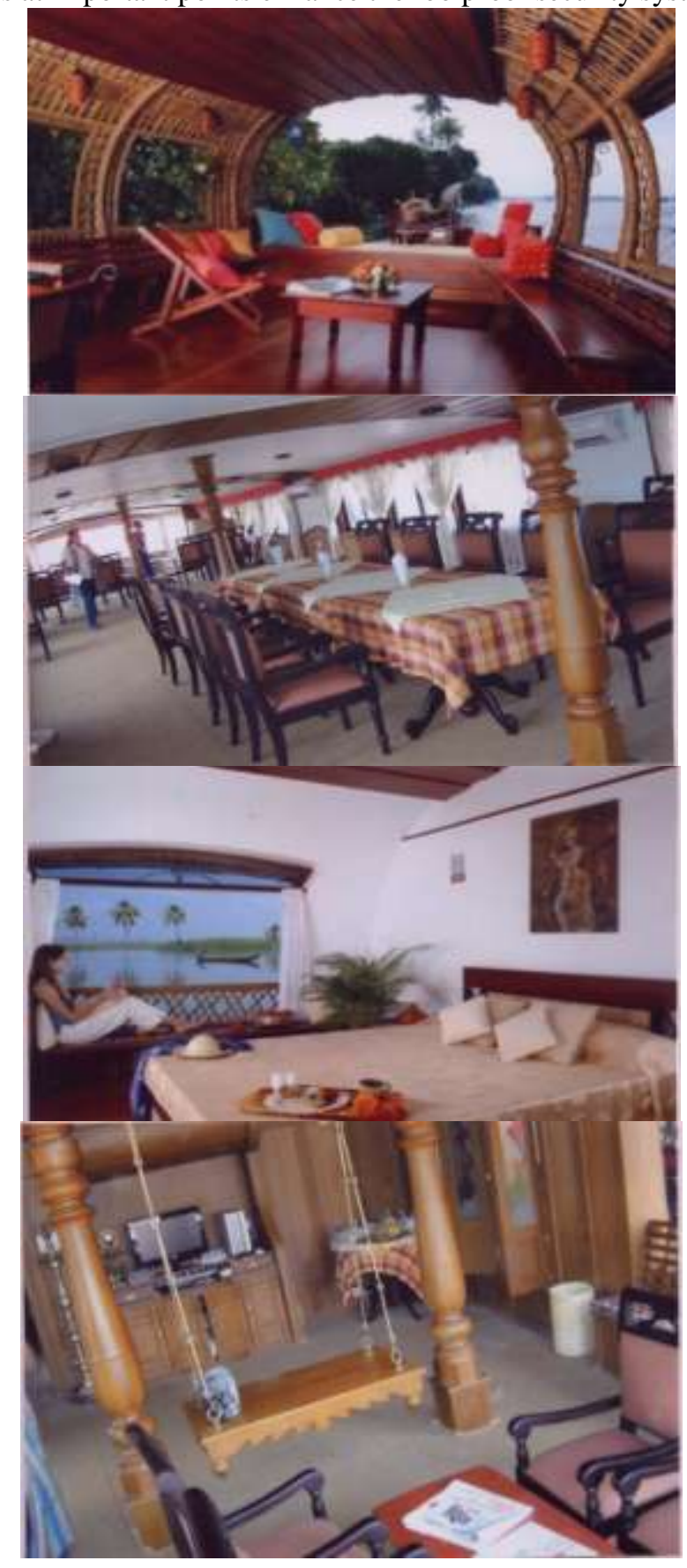




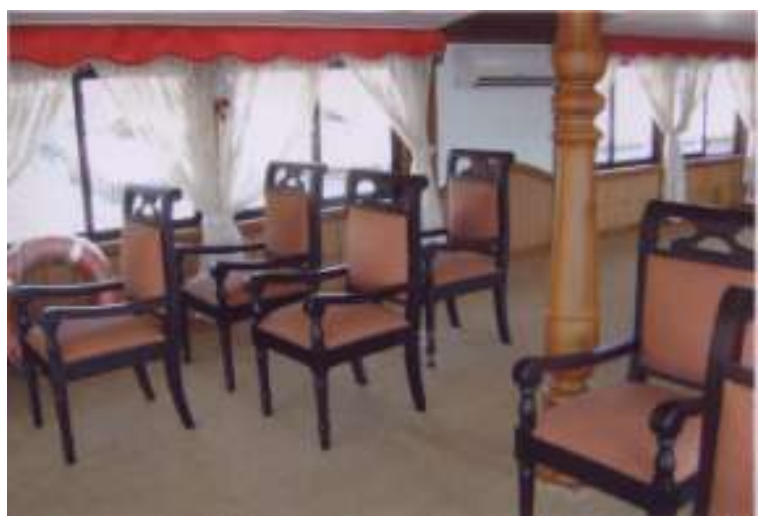

Toilet:

The houseboat is provided with clean and modern eco-friendly toilets. The walls and floors are fixed with ceramic tiles in order to ensure the hygiene and beauty. Stylish and quality bathroom fixtures such as water closets, wash basin, shower units, focuses and ensure passenger's comfort and give a feel at home.

\section{Kitchen:}

The passengers are served with sumptuous and delicious foods of intercontinental nature. House boats are provided with spacious modern kitchen in the house. To prepare the food items, sufficient storage facilities including cold storage, refrigerators are provided in the kitchen. Other modern requisites like oven, stove and kitchen cutleries are also provided.

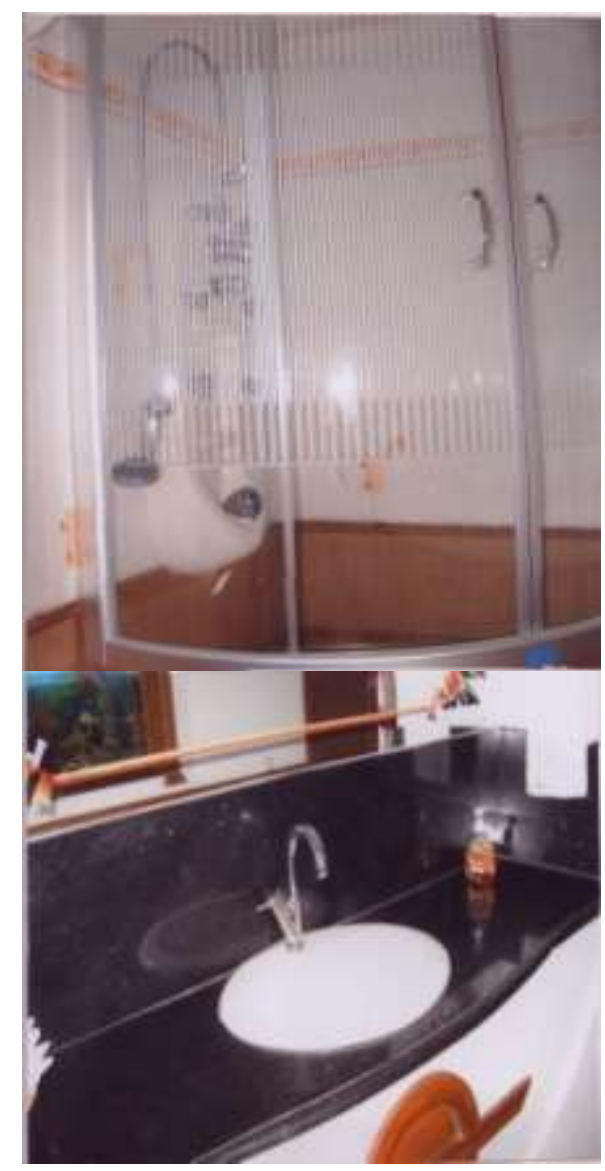

\subsection{Impact of houseboats on Environment}

A study conducted by School of Planning and Architecture and Kerala State Pollution Control Board, in Alappuzha district reveals that houseboats in the district are "killing" Vembanad Lake, the largest wetland ecosystem in south India, by dumping huge amount of waste into it. This is also destroying the fish wealth in the lake.(Sajimon P S,2012)[17] 
Pollution of backwaters and other water bodies due to tourism activities is a major concern. Tourism Department, in association with Kerala State Pollution Control Board, have taken stringent measures to see that all the houseboats will have scientific solid and liquid waste management system and use only 4 stroke engines. Department will also explore possibilities of introducing these systems in other tourists boats. Number of houseboats plying in the backwaters of Kerala have increased and there is an urgent need to evaluate the safety and service standards of houseboats and classifying them accordingly. This will be the first step towards sustaining this unique tourism product of Government of Kerala. (Oommen.P.C ,2003)[18]

Every time there is a public outcry on pollution of water-bodies in Kuttanad, particularly the Vembanad Lake, the 600-odd houseboats operating in the region are among the first to be blamed. But the ground reality reveals that though there is no denying the role of the houseboats in pollution, there are a few others too who have an indirect but definite share of the blame. Irresponsible tourism has destabilized the villages where their life has been affected adversely. Oil spills from the around 800 operating houseboats there destroys paddy cultivations, and also render the water frequently undrinkable._BeychokM.R.1971)[19]

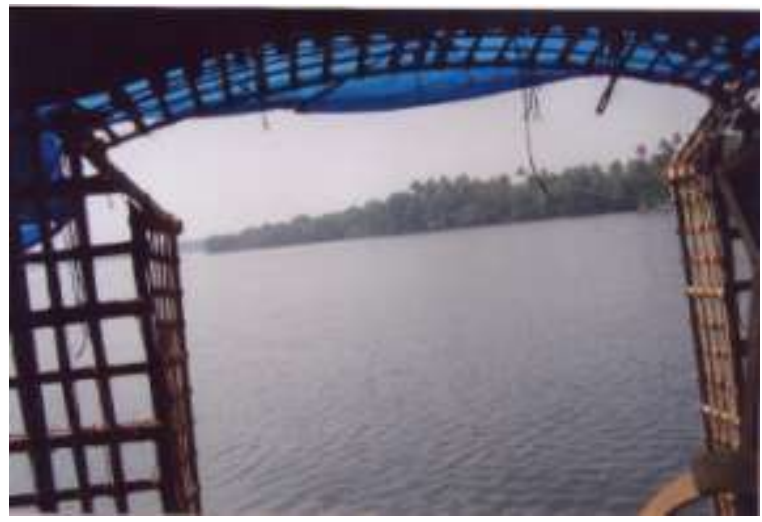

\subsection{Specifications for Houseboat service}

According to the assessment made on the subject, there are 14 river systems in India, which cover $83 \%$ of its physical area, $80 \%$ of its population, and $85 \%$ of its surface run off. Several bodies have been engaged in our country for the task of collecting and analyzing water samples from these river basins, so as to work out the water quality profiles for all the river basins.(Garg,S.K, 2008)[20]

When untreated sewage is discharged into the river streams, floating solids present in that may be washed up on to the shore, near the point of disposal, where they decompose and create foul smells and bad odors. The large amount of organic matter present in the discharged sewage will also consume the dissolved oxygen from the river stream in getting oxidized thus decreasing the oxygen of the river streams, causing fish kills and other undesirable effects (Garg,S.K, 2008)[20]

The Kerala State Pollution Control Board (PCB) taking action against houseboats that lack arrangements to check pollution and are operating without PCB clearance in the wake of increase in pollution in the lake and the spread of diseases in Alappuzha district. The operation of houseboats without any machinery to control pollution will only aggravate the situation. Hence, the PCB has decided to take action as per law without further notice against houseboats that are functioning without their own or common machinery for the treatment of waste in the bio tanks (Mahindro.S.N 2004[21]

The Lok Ayukta had issued orders directing that a waste treatment plant be set up for treating the waste in the bio-tanks of the houseboats. But the houseboat owners were reluctant to implement the order. A plant has been set up at Punnamada in Alappuzha district.(The Hindu, $2^{\text {nd }}$ August 2007,[22]

Biological filters are suitable for treatment of septic tank effluent where the soil is relatively impervious(percolation rate>60minutes)or in water logged areas, or where limited land area is available.( Garg,S.K, 2008)[20] 


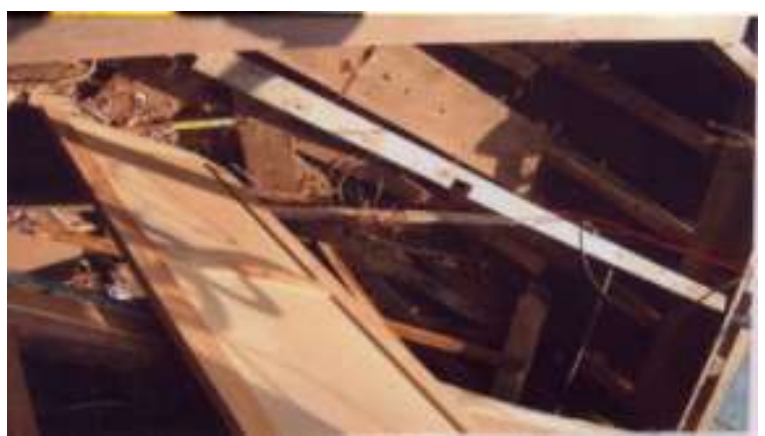

Bioseptic tank being constructed under the deck of the houseboat near driving seat

IV. Criteria For Classification Of Houseboats

4. Criteria for classification of houseboats (www. cocohouseboatskerala.com) [23]

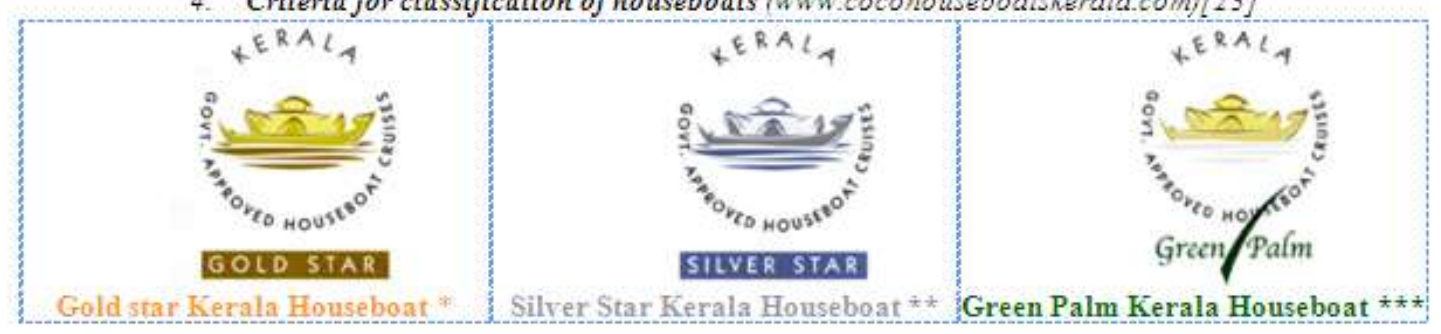

Gold Stat Houseboats are deluxe category houseboats with less pollution.
Silver Houseboats are standard category houseboats with less pollution.
Star** Hon mechanized Houseboats, punting/ electric engine houseboats non polluting.
Green
Palm *** Non

\section{'Gold Star' and 'Silver Star'}

This covers the quality of the houseboats - materials used for their construction, facilities offered by them, the quality of furniture, services, and the safety and security measures. Oommen.P.C 2003)[18]

Houseboats which satisfy all the essential conditions and at least five of the optional conditions are awarded the 'Gold Star' certification, while others satisfying the essential conditions are given a 'Silver Star' classification.

\subsection{Optional conditions for 'GOLD STAR'}

- The general construction of the houseboat should show distinctive qualities of luxury

- The houseboat should be furnished with superior quality carpets, curtains, furniture etc.

- Alternate arrangements for discharging solid wastes and sewage, like scientifically designed septic tanks and chemical toilets.

- Houseboats should be battery operated

- Provision of 24 hour electricity on the houseboat board for lights and fans

- Provision for 24 hour hot and cold running water.

- Availability of water purification system, on board.

- Provision of a refrigerator or icebox on board

- Arrangements for providing the guests menu of their choice

- Staff interacting with guests should be experienced and fluent in English.

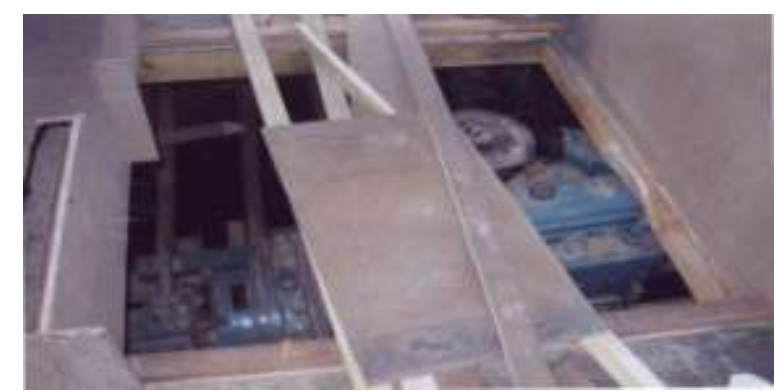

Generator with 2800 watts capacity 


\section{2‘Green Palm’ Certifications for Eco-friendly Measures}

Houseboats satisfying the essential conditions and adhering to eco friendly measures prescribed by the department of tourism will be awarded the 'Green Palm Certification', a symbol of eco-friendliness-the top classification awarded by the department for eco friendly houseboats. Specifications for obtaining this certification include mainly non-discharge of solid wastes and sewage directly to the water; alternative arrangements for disposal of solid wastes and sewage by providing scientifically designed septic tanks or biochemical toilets, and use of environmentally-friendly materials and local employment.(TheTimes of India,2012)[24] and Tchobanoglous, G., Burton, F.L., and Stensel, H.D. (2003)[25]

Same conditions are recommended for houseboats for approval by Tourism department along with the following conditions.

- Houseboats approved by the Department of Tourism should fly a flag inscribed with the mnemonic of

the accorded status.

- The flag will be approved by the Department of Tourism.

- Houseboats satisfying the essential conditions and adhering to eco-friendly measures prescribed by the Department of Tourism will be awarded the Green Palm Certificate..

- Alternate sources of energy for fuel, like solar power, to be used for heating, lighting etc.

- Arrangement of a system of separating the recyclable from non-recyclable garbage. There by organizing the disposal of non-biodegradable garbage in such a manner so that the natural environment is not harmed.

- Use of paper bags, cloth bags and other alternatives instead of polythene bags, wherever possible.

- Use of recycled paper for stationery and other publicity materials.

- Use of locally available ethnic materials for construction of houseboats and furniture. At least $75 \%$ of the workers in a houseboat should be employed from districts of the houseboat's operation.

- Houseboats using out board engines should acquire a pollution control certificate every three months from a competent authority.

\section{Conclusion}

The study threw light on the materials used and the methods of construction of houseboats which form an integral part of tourism in Kerala. Due to the high literacy rate in Kerala people are also aware of the hazards of water pollution and hence majority of the house boats which ply in Kerala adhere to the standards imposed by the government and Pollution Control Board.

This is only a case study and hence only one houseboat company's facilities and norms could be studied. Further research could be carried out by taking into consideration other houseboats' facilities and standards.

- Four main Areas to develop are environment, energy, water and propulsion

Environment: Technology - water pollution control - noise pollution control - waste management, efficient treatment - recycling technology.

Energy: Solar - Renewable - Alternative (wind) - Energy conservation.

Water: conservation - water treatment - Filtration and purification - pumps and valves - waste water sewage treatment - biochemical systems.

Propulsion: Inboard 120volt DC motor - Controller - battery - solar panel - water tight / sound proof engine room. (Massoud Tajrishy and Ahmad Abrishamchi,2005)[26]

The sustainability of eco - tourism and promotion of green palm should be the motto of the project. Less fuel/running cost, no oil or diesel contamination into the backwaters, no untreated sewage into the backwater and reduction in noise pollution. Dream for a green and pleasure future in backwaters and save the backwaters for the new (next) generation. Green palm houseboat is working today for a cleaner tomorrow

\section{Acknowledgement}

Acknowledgements are due to the Manager, Muthoot River Escapes (MRE) - group, Alleppey and Mr. Joseph Chandy, Architect, Kochi and Miss.Sreelalitha, Shazia K.Ashraf and Felsy Kuruvilla (the students of Designing Interiors and Exteriors) for helping to carry out this project successfully.

[1] Ministry of Tourism, Government of India,2009

References

WTTC, Travel and Tourism Impact, India 201

http://www.Kerala-india-tourism.com/Kerala

Jaspal Singh (2001) Methodology \& Technique of Research. Kanishka Publishers, Distributors. New Delhi.pp.200-245

Sidhu,S.K. 1984.Methodology of Research in Education, Sterling Publishers Pvt. Ltd.New Delhi

Kerala State Pollution Control Board,2008 http://en.wikipedia.org/wiki/Rivet

Loewenstein , K.L.(1973). The Manufacturing Technology of Continous Glass Fibers. New York: Elsevier Scientific, P. 2 
[8] Lubin, George(Ed.), 1975, Handbook of Fiberglass and Advanced Plastic Composites. Huntingdon NY.Robert E.Krieger.

[9] MohrJ.G and Rowe,W.P,1978, Fiberglass., Atlanta., Van Nostrand Reindhold.

[10] PSI-95, American Plywood Association,2001

[11] Segui, William T,2007- steel design4th edition,Thomson,Toronto, wikimedia

[12] RaoA.G. M and Murthy D.S.R, 1995-Appropriate technologies forlow cost housing, Oxford \&IBH Publishing Co, Pvt. Ltd,New Delhi,P. 117 http//www. Wikipedia.org/marine plywood

[13] Volf Milos .B 1990 Technical Approach to Glass. New York: Elsevier.

[14] 17. Sajimon P S,2012 [17] TIMES OF INDIA-KOCHI Waste from houseboats killing Vembanad Lake, 18. 18. Oommen.P.C ,2003 "Toursim - Travel directory of Kerala. United Communications", Trivandrum

[15] BeychokM.R.1971 "Performance of surface aerated basins" Chemical Engineering Progress symposium Series 67(107):322-339 www.CSA illumina.com

[16] Garg,S.K, 2008, Sewage Disposal and Air pollution Engineering, Khanna Publishers, Delhi P. 473

[17] Mahindro.S.N 2004, Potable Water. APH Publishing Corporation. New Delhi pp.87-98,194-196.

[18] The Hindu, $2^{\text {nd }}$ August 2007, The Hindu Daily, Kochi edition, P.12 www.cocohouseboatskerala.com

[19] TheTimes of India- Kozhikode TNN May 18, 2012, Alappuzha set to make Vembanad lake plastic-free

[20] Tchobanoglous, G., Burton, F.L., and Stensel, H.D. (2003). Wastewater Engineering (Treatment Disposal Reuse) / Metcalf \& Eddy, Inc., 4th Edition, McGraw-Hill Book Company. ISBN 0-07-041878-0.

[21] Massoud Tajrishy and Ahmad Abrishamchi,2005- Integrated Approach to Water and Wastewater Management for Tehran, Iran, Water Conservation, Reuse, and Recycling: Proceedings of the Iranian-American Workshop, National Academies Press 